茖

SSCL-Preprint-250

May 1993

Distribution Category: 400

G. M. Brown

\title{
Measurement of Complex Surfaces
}

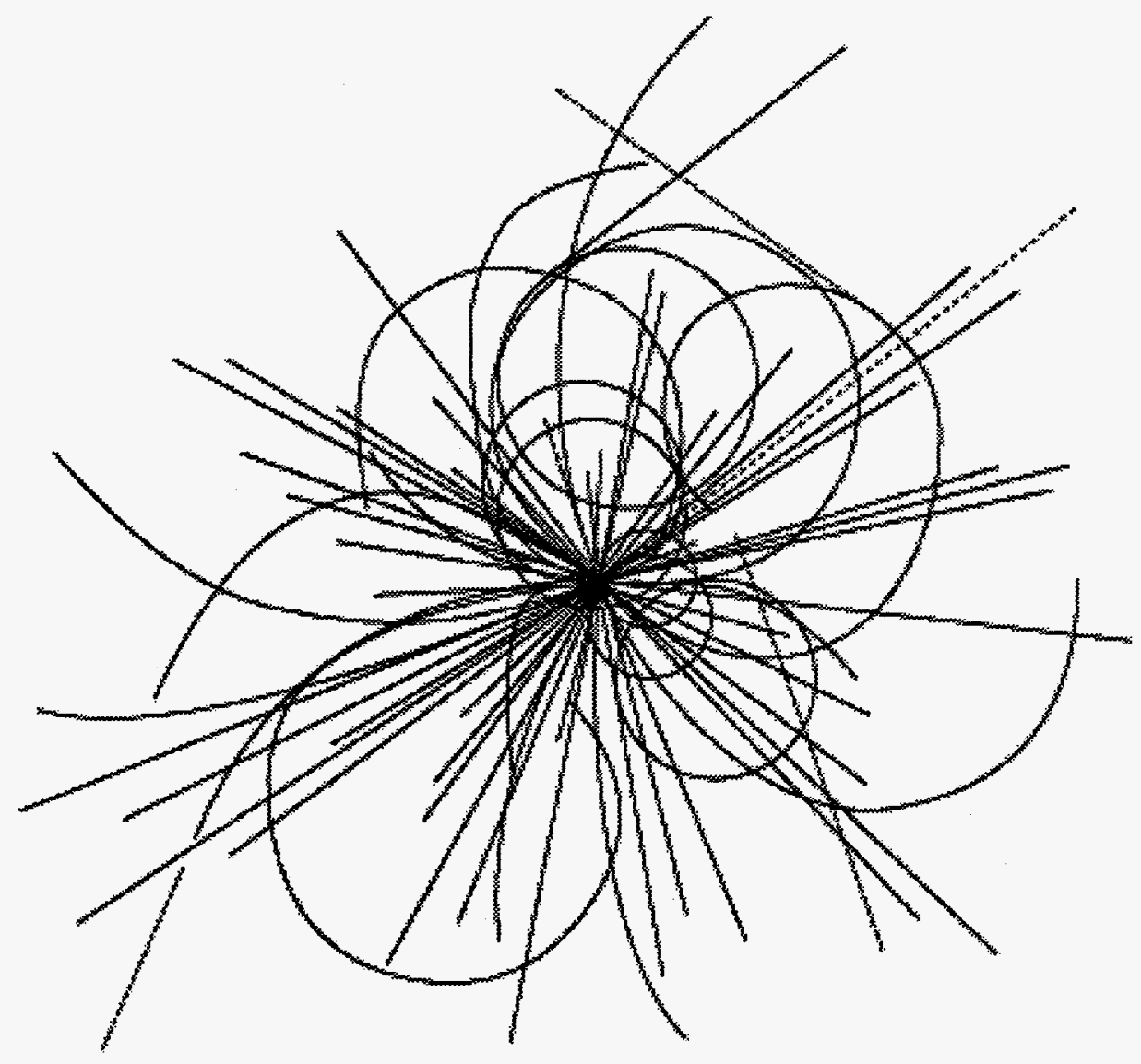

Superconducting Super Collider Laboratory

APPROVED FOR RELEASE OR

PUBLIGATION - O.R. PATENT GROUP BY.. E.......DATE. $/ / .7 / 9.20$ 


\section{Disclaimer Notice}

This report was prepared as an account of work sponsored by an egency of the United States Govemment. Nelther the United States Government or any agency thereof, nor any of their employees, makes any warranty, express or implied, or assumes any legal liability or responsibility for the accuracy, completeness, or usefulness of any information, apparatus, product, or process disclosed, or represents that its use would not infringe privately owned rights. Reference herein to any speclfic commercial product, process, or service by trade name, trademark, manufacturer, or otherwise, does not necessarlly constitute or imply lts endorsement, recommendation, or favoring by the United States Government or any agency thereof. The views and opinions of authors expressed herein do not necessarily state or reflect those of the United States Govemment or any agency thereof.

Superconducting Super Collider Laboratory is an equal opportunity employer. 


\section{DISCLAIMER}

Portions of this document may be illegible in electronic image products. Images are produced from the best available original document. 
SSCL-Preprint-250

\title{
Measurement of Complex Surfaces
}

\author{
G. M. Brown \\ Superconducting Super Collider Laboratory* \\ 2550 Beckleymeade Ave. \\ Dallas, TX 75237
}

May 1993

*Operated by the Universities Research Association, Inc., for the U.S. Department of Energy under Contract No. DE-AC35-89ER40486. 


\title{
MEASUREMENT OF COMPLEX SURFACES
}

\author{
Graham M. Brown \\ Superconducting Super Collider Laboratory* \\ 2550 Beckleymeade Ave. \\ Dallas, TX 75237
}

\section{INTRODUCTION}

Several of the components used in coil fabrication involve complex surfaces and dimensions that are not well suited to measurements using conventional dimensional measuring equipment. Some relatively simple techniques that are in use in the SSCL Magnet Systems Division (MSD) for incoming inspection will be described, with discussion of their suitability for specific applications.

Components that are submitted for MSD Quality Assurance (QA) dimensional inspection may be divided into two distinct categories; the first category involves components for which there is an approved drawing and for which all nominal dimensions are known; the second category involves parts for which 'reverse engineering' is required, the part is available but there are no available drawings or dimensions. This second category typically occurs during development of coil end parts and coil turn filler parts where it is necessary to manually shape the part and then measure it to develop the information required to prepare a drawing for the part.

Measurement of three-dimensional components is normally performed on a coordinate measuring machine (CMM) and it is important to briefly review here some of the operational characteristics of these machines. A touch sensitive probe with a spherical tip is used to contact the surface of a component and the CMM initially records the position of the center of the spherical tip. It is not possible to directly measure points along an edge. The probe center position is then compensated by the probe radius, to determine the actual location of the contact point. In the case of surfaces that consist of planes, lines and circular or cylindrical features, this compensation can be performed by standard geometric techniques. In the case of complex surfaces, this compensation can only be performed when the probe approaches the surface along the direction of the surface normal. The magnitude of the probe correction depends on the tip diameter and on the deviation of the approach direction from the surface normal. It might appear possible to eliminate the need for compensation by using a 'point' probe. Examinations of typical 'point' probe tips on an optical comparator have shown tip radii of the order of $0.075 \mathrm{~mm}$. This dimension is $75 \%$ of a typical total profile tolerance for coil end parts.

*Operated by the Universities Research Association, Inc., for the U.S. Department of Energy under Contract No. DE-AC35-76SF00098. 


\section{MEASUREMENT OF COMPONENTS WITH DEFINED SURFACES}

A typical coil end part is shown in Figure 1. This part is fabricated as the intersection of two ruled surfaces with the inner and outer surfaces of a cylinder. The inner and outer ruled surfaces are each defined by a total of 400 points along the intersections of the ruled surfaces with the surfaces of the cylinder ( 2 intersections $* 2$ symmetry about a longitudinal axis * 2 edges * 50 points per edge). Coordinates of these points are available from the computer assisted design (CAD) system, but surface normals are not available. A ruled surface has one of the principal radii of curvature equal to infinity and it is important that this feature be maintained during fabrication. Some care is required in programming numerical control machining systems to generate ruled surfaces; the standard method of determining a tool path by connecting defined points with spline curves and generating a surface from those curves does not usually result in a ruled surface.

The approach used for inspection of components with surfaces defined by ruling lines is as follows:

- straight lines are generated between corresponding ruling points on the inner and outer cylinder surfaces, these lines are the ruling lines used to define the surface.

- point coordinates are calculated at the one-third and two-third length locations along the lines. The selection of these fractions is somewhat arbitrary. Any position sufficiently far from the edge for good data would be acceptable.

- for all ruling lines other than those at the ends of the surface, approximate normals are generated from the vector product of vectors drawn along the diagonals of a panel formed from the ruling lines on either side of the line under consideration. At the panel ends, approximate normals are calculated from the end ruling line and the line adjacent to it. This method can be shown to produce approximate normals that are typically within +-5 degrees of the actual surface normal and the cosine correction for deviations from the actual surface normal can be neglected.

- a 'vector touch' is performed at each of the calculated points, along the calculated normal to the surface (Actually, to the point on the surface that lies on the line through the nominal point with the calculated normal direction. This method requires operation of the $\mathrm{CMM}$ under program control and with small target tolerances).

- the distances between the nominal and actual points can then be calculated and compared with the allowed tolerance. This task is simplified by printing, in addition to the actual measured and nominal data, a table in which the condition of each point is denoted by a one-character symbol that shows the degree of deviation from the nominal value.

A standard inspection program has been written to read nominal point coordinates from a data file and perform the inspection of many different parts based on the information in the file. A standard tip definition file that lists all required probe tip orientations is used with a general calibration program for automatic calibration of all required tips, and to verify in the inspection program that all required tip calibrations have been performed prior to the start of the inspection.

This method is reliable and measurements on metal components typically show repeatability within the nominal CMM specifications ( $+0.005 \mathrm{~mm}$ ). Measurements on glass-reinforced epoxy components typically show repeatability of $+-0.02 \mathrm{~mm}$. The degradation is primarily atributed to surface irregularities of the composite and to slight variations in the actual probe locations in repeated measurements. Repeatability on measurements of composites can be improved by decreasing the allowed touch probe target tolerances. CMM hardware does impose a lower limit on target tolerance values.

\section{MEASUREMENT OF COMPONENTS WITH ARBITRARY SURFACES}

In the case of components with surfaces that do not consist of points with known coordinates (see Figure 2) direct probe compensation is not possible and a more complex 
approach is required. If a set of points is measured without probe compensation, the measured values will correspond to points on a surface that is locally parallel to the desired surface and distant from it by one probe radius along the local surface normal. CAD programs with three-dimensional capability allow the translation of the measured surface along local surface normals by a prescribed distance.

One approach that has been used successfully is as follows

- divide the surface to be measured into a set of adjoining quadrilaterals, with (possibly) a different probe tip orientation for each quadrilateral. The size of each quadrilateral depends on the configuration of the surface and on the available access for the probe tip. The normal to the best-fit plane through the vertices of the quadrilateral is used to determine the direction of approach to the surface and points are measured without probe compensation. - divide each quadrilateral into geometrically similar subelements, based on a maximum step size along each of the two lines intersecting at a specified boundary corner of the quadrilateral.

- measure points at each of the interior points and along the boundary of each quadrilateral. Measured values are written to a disk file in a format appropriate for data input to a CAD program.

- use the points in this data file to generate a three-dimensional CAD surface that is then translated in the appropriate direction along the local surface normals by one probe radius, to generate a surface that corresponds to the actual measured surface.

It might appear that this would be an efficient method for measuring the ruled surfaces discussed in the previous section. In fact, due to CAD limitations, comparisons between actual and nominal positions become very difficult if this approach is used. Ideally, it requires a general three-dimensional surface fitting routine that supports all six degrees of freedom in determining the best fit between two surfaces, and with the ability to determine distances between two surfaces along the normals to one surface at prescribed points on that surface. The problem is further complicated by the fact that the total component consists of several individual surfaces with discontinuous curvatures at their intersections and the bestfit is required on all surfaces simultaneously.

\section{SUMMARY}

Two techniques have been presented for measurement of the complex surfaces typically found in the coil end pieces of superconducting magnets. Applicability criteria have been listed, together with some limitations of existing hardware and software. 


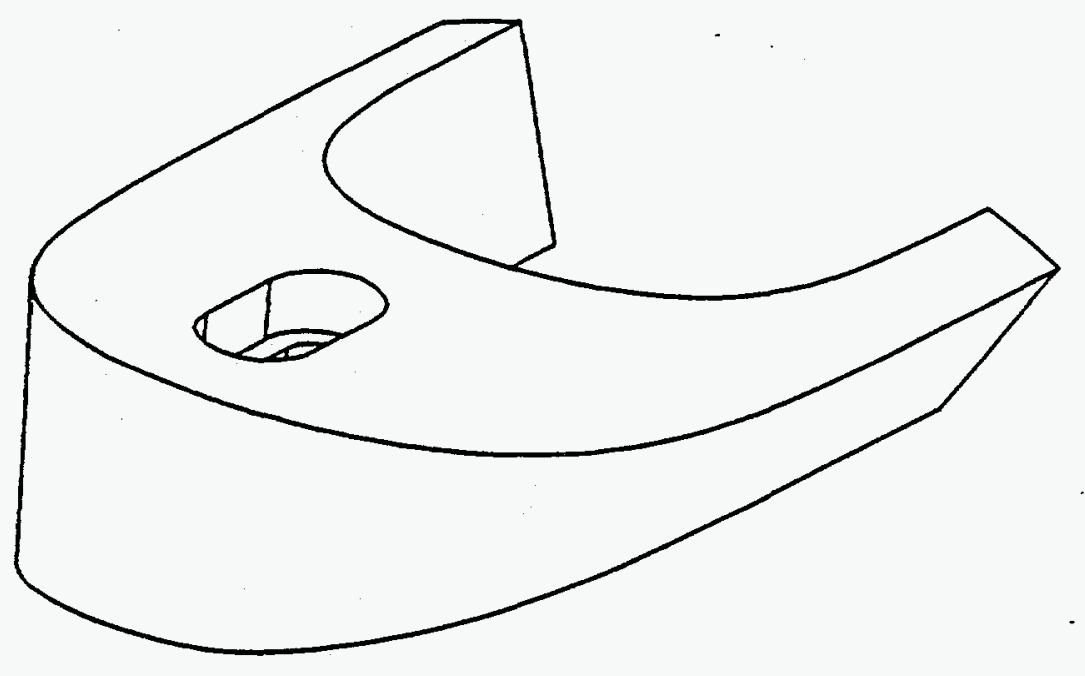

Figure 1 A typical part constructed from ruled surfaces and concentric cylinders

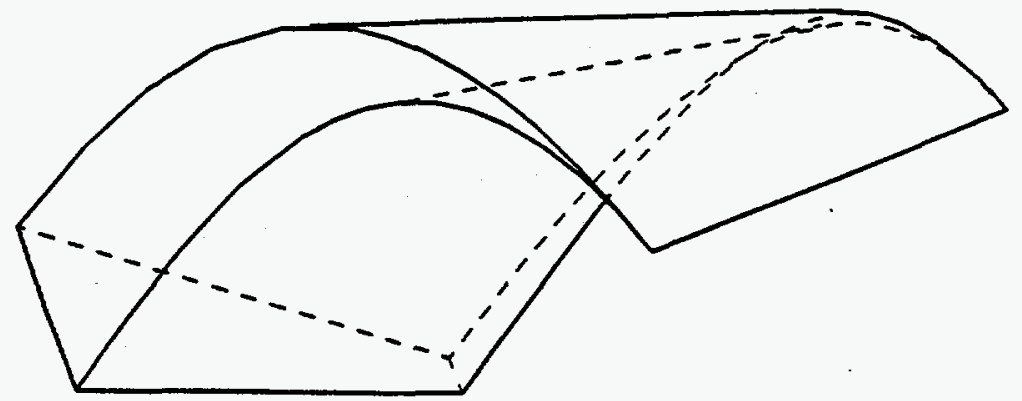

Figure 2 A typical part constructed from arbitrary surfaces 